\title{
Junior High School Deaf Students' Analysis of Multirepresentation Ability in SMPLBN Ungaran
}

\author{
Tina Anggraini ${ }^{1}$, Sunyoto Eko Nugroho ${ }^{2}$, Bambang Subali ${ }^{3}$ \\ 1,2,3Physics Education Graduate School, Universitas Negeri Semarang,Indonesia Coresponding email: \\ ${ }^{1}$ Corresponding email: tinaanggraini45@yahoo.co.id
}

\begin{abstract}
Abstrack
This study's purpose is to determine the ability of multirepresentation of students with special needs after problem-based learning model applied. Deaf students need multiple representations to make it easier to understand subjects especially on physical materials. The method used in this research is mixed methods with triangulation design. The subject of this research is deaf students in SMPLB Negeri Ungaran. Required data include is the result of multirepresentation capability test. The result of the research shows that the big improvement of multirepresentation ability of students with problem-based learning model is 0.32 . Categorization for multirepresentation capability are 3 high category students, 5 medium category students, and 1 low category student.
\end{abstract}

Keywords: Multirepresentations, Deaf students, Problem-based learning

\section{Introduction}

Physics subject matter consists of several concepts which are usually abstract both symbols used and theories. The concept of physics requires direct interaction with natural phenomena related to the real world. Most students still experience difficulties in understanding various representations of various real-world problems, in fact this is important in learning science including physics. During learning, students are guided to be able to choose and master which concepts are in accordance with existing events and ways to illustrate in various forms of representation (Singer \& Smith, 2013). Students' ability in understanding material is certainly different, including Children with Special Needs (ABK).

Children with special needs are children who have abnormalities from normal child conditions both in terms of physical, mental and social behavior (Krezmien, Mulcahy, University--suny, \& Leone, 2008). Children with special educational needs need psychological education and special assistance and special learning conditions during the learning and training process (Didenko \& Frantseva, 2016). One student with special needs who has limited learning is deaf students. Deaf students have limitations in receiving information, especially those that are auditive which can inhibit cognitive development (Vermeulen, Denessen, \& Knoors, 2012). In connection with the physics material that has a lot to learn about the interactions of various physical quantities, an explanation is needed using the form of representation (Singer \& Smith, 2013). The use of various representations can make it easier for students to remember the subject matter for longer. The appearance of various representations in the planting concept makes it easier for students to understand the concept (Demirbag \& Gunel, 2014).

Presentations include verbal, visual/ image/ graphic, and mathematical representations. Verbal representation is a representation in verbal form or in the form of an explanation of a problem. Image representation is a representation that is presented in the form of an image. Graph representation can be used as a means to visualize complex verbal statements (Smetana, Odelson, Burns, \& Grisham, 2009). Mathematical representation is a representation to solve quantitative problems.

The use of several learning approaches or models that teachers need to apply to special education (Nishimura, 2014). The learning model is a constructivistic model that can improve students' competencies and thinking skills, one of which is a problem-based learning model (PBM). Problem-based learning has three perspectives, PBM as an investigation process, as a learning process and as a constructivist approach (Schmidt G, Rotgans, \& Yew, 2011). Problem-based learning allows students to learn complexes that prioritize knowledge and practice (Hmelosilver et al., 2007). Problem-based learning is active learning that can develop understanding of concepts and reduce the level of misconception (Akinoglu \& Özkarde, 2007). The use of PBM in learning trains students to 
apply what is known in daily life. Real-world context problems are an important component in problem-based learning (Mykytyn, Pearson, Paul, \& Peter P. Mykytyn, 2008)

Based on observations at State Unpad Unpad School of Mathematics and Natural Sciences is also said to use the 2013 curriculum. The pedagogical ability of teachers in applying learning models is needed in this curriculum which plays an active role in influencing the learning process of deaf students (Vermeulen et al., 2012). This statement can support the use of problembased learning models to encourage students to construct their own knowledge. Based on the problems that have been submitted, the research aims to find out the ability of multi representation and analytic thinking with problem-based learning for deaf students with Vibration and Wave material..

\section{Metods}

The research method used is concurrent mixed methods strategy by collecting concurrent or one-time quantitative and qualitative data. Place of study in State High School Ungaran in even semester of 2017/2018 school year. The learning process is applied to problem-based learning models to determine the multi-representation ability of deaf students. The next stage takes the data of multi-representation ability research with a written test.

The study population was the eighth grade students of State Junior High School Ungaran where deaf students were used as samples. Sampling was carried out by purposive sampling technique which determines the sample using certain considerations. Students are in a class that has been determined by the policy of an extraordinary school and in accordance with the research objectives.

The instruments in learning are learning tools consisting of syllabus, RPP, PBM-based student discussion sheets, and questions, and observation sheets. The research data is obtained from the results of pre-tests and postpresentation skills of students.

\section{Result}

The study began with an initial observation in the State Ungaran SLB to find out the conditions in the school. This activity was also carried out to determine the research sample used in the study. The results obtained are the students' initial data which is seen from the average value of State Unpad high school students who are low in vibration and wave material compared to other materials.

The final data analysis was done by using the gain test to determine the magnitude of the improvement in the ability of multirepresentation of deaf students before and after problem-based learning. Before the learning process students are given a pre-test to determine the students' initial abilities and after the learning process is given a post-test. Based on the calculations obtained, obtained for the average pre-test value of 43 , the average post-test value is 61 , and the gain value is 0.32 .

The results of the study show that the average multi-representation ability of students has increased. The ability of verbal, visual / image, and mathematical representations can be seen in Table 1 .

Table 1 Multi representation capability

\begin{tabular}{ccl}
\hline $\begin{array}{c}\text { Pre-test } \\
\text { average }\end{array}$ & $\begin{array}{l}\text { Post-test } \\
\text { average }\end{array}$ & $\begin{array}{l}\text { Gain } \\
\text { Value }\end{array}$ \\
\hline 43 & 61 & 0.32
\end{tabular}

The results showed that there was an increase in the ability to represent multiple deaf students with problem-based learning models. The multi-representation ability of these students is different because the characteristics of deaf students are different. Based on the results of the study also showed that each representation was in the low, medium, or high category.

The categorization of students' multirepresentation abilities can be seen in Table 2 .

Table 2 Categorization of multi representation capabilities

\begin{tabular}{ccc}
\hline Category & Frequency & $\begin{array}{c}\text { Percentage } \\
\text { Value }(\%)\end{array}$ \\
\hline High & 3 & 33.3 \\
Medium & 5 & 55.6 \\
Low & 1 & 11.1 \\
\hline
\end{tabular}

Based on the results of the study, the multi-representation ability of deaf students in problem-based learning models has increased. Problem-based learning presents information related to daily life that can be directly 
observed in the classroom. The problems presented grow the mindset of students to be able to link the concept of one to another. Problem-based learning provides greater control over learning than with conventional learning that emphasizes real learning and motivates (Walker \& Leary, 2009). Deaf students see events directly during the learning process, allowing students to understand the subject matter and be able to express in various forms of representation. The multirepresentation ability of deaf students increases with problem-based learning. This happens because during the learning process deaf students can see the physical problems directly for wave material that allows students to understand the material in more depth. Students who usually learn only by paying attention to the teacher's explanation can immediately learn by themselves even with their hearing conditions are lacking. Students are also able to remember longer material they have learned with their respective abilities. Research (Demirbag \& Gunel, 2014) explained that multi representation is not only focused on learning research but also for theoretical learning. Therefore, student representation also needs to be considered to find out their level of understanding.

During the learning process students can choose interesting problems to solve so they become motivated to play an active role (Mykytyn et al., 2008). Deaf students in the school also seem to have an interest in discussing with their friends when they take part in learning. Students become active during learning because of their curiosity by expressing their opinions to friends and teachers. This affects learning activities to become more active. Problem-based learning allows students to be involved in learning realworld problem solving skills, learning to dig information, and independent learning in accordance with the learning objectives in schools with special needs (Hmelo-silver et al., 2007).

\section{Conclusion}

Based on the results of the study it can be concluded that the multi-representation ability of deaf students after learning with problembased learning models has increased. This is because problem-based learning is able to make students active during learning.

\section{Refferences}

Akinoglu, O., \& Özkarde, R. (2007). The Effects of Problem-Based Active Learning in Science Education on Students 'Academic Achievement , Attitude and Concept. Eurasia Journal of Mathematics, Science \& Technology Education, 3(1), 71-81.

Demirbag, M., \& Gunel, M. (2014). Integrating Argument-Based Science Inquiry with Modal Representations: Impact on Science Achievement , Argumentation, and Writing Skills *. Educational Sciences: Theory \& Practice, 14(1), 386-391. https://doi.org/10.12738/estp.2014.1.163 2

Didenko, I. A., \& Frantseva, E. N. (2016). Features of interaction between preschool teachers and "special" children and their parents. Procedia - Social and Behavioral Sciences, 233(May), 459462.

https://doi.org/10.1016/j.sbspro.2016.10. 190

Hmelo-silver, C. E., Duncan, R. G., Chinn, C. A., Hmelo-silver, C. E., Duncan, R. G., \& Chinn, C. A. (2007). Scaffolding and Achievement in Problem-Based and Inquiry Learning: A Response to Kirschner, Sweller, and Scaffolding and Achievement in Problem-Based and Inquiry Learning: A Response to Kirschner, Sweller, and Clark ( 2006 ). Educational Psychologist, 42(2), 99-107. https://doi.org/10.1080/00461520701263 368

Krezmien, M. P., Mulcahy, C. A., University-suny, B., \& Leone, P. E. (2008). Detained and committed youth: Examining differences in achievement, mental health needs, and special education status. Education and Treatment of Children, 31(4), 445-464.

Mykytyn, K., Pearson, A., Paul, S., \& Peter P. Mykytyn, J. (2008). The Use of ProblemBased Learning to Enhance MIS Education. Decision Sciences Journal of Innovative Education, 6(1), 89-114. https://doi.org/10.1111/j.1540-

4609.2007.00160.x 
Nishimura, T. (2014). Effective professional development of teachers: A guide to actualizing inclusive schooling. International Journal of Whole Schooling, 10(1), 19-42.

Schmidt G, H., Rotgans, J. I., \& Yew, E. H. (2011). The Process of Problem Based Learning: What Works and Why. Medical Education, (45), 792-806.

Singer, S., \& Smith, K. A. (2013). DisciplineBased Education Research: Understanding and Improving Learning in Undergraduate Science and Engineering. Journal of Engineering Education, 102(4), 468-471. https://doi.org/10.1002/jee.20030

Smetana, L., Odelson, D., Burns, H., \& Grisham, D. L. (2009). Using Graphic
Novels in the High School Classroom: Engaging Deaf Students With a New Genre. Journal of Adolescent \& Adult Literacy, 53(3), 228-240. https://doi.org/10.1598/JA

Vermeulen, J. A., Denessen, E., \& Knoors, H. (2012). Mainstream teachers about including deaf or hard of hearing students. Teaching and Teacher Education, 28(2), 174-181. https://doi.org/10.1016/j.tate.2011.09.007

Walker, A., \& Leary, H. (2009). A Problem Based Learning Meta Analysis : Differences Across Problem Types , Implementation Types, Disciplines, and Assessment Levels. The Interdisciplinary Journal of Problem Based Learning, $3(1)$, 6-28. 